\title{
COMPARACIÓN DE GANANCIAS DE PESO EN BOVINOS REYNA-JERSEY Y JERSEY, DURANTE LA ETAPA DE DESARROLLO ${ }^{1}$
}

\author{
Claudio Fabián Vargas-Rodríguez ${ }^{2}$
}

\begin{abstract}
RESUMEN
Comparación de ganancias de peso en bovinos Reyna-Jersey y Jersey, durante la etapa de desarrollo. El presente estudio se realizó en la Estación Experimental Alfredo Volio Mata de la Universidad de Costa Rica durante el 2006 y 2007 con la intención de cuantificar las diferencias y posibles ventajas que se pueden infundir al implementar la raza Reyna en un sistema especializado, evaluando la ganancia de peso de seis animales Jersey puros en comparación con seis animales $1 / 2$ Reyna- $1 / 2$ Jersey durante su periodo de desarrollo. Los animales $1 / 2$ Reyna- $1 / 2$ Jersey ganaron peso a razón de 0,7265 $\mathrm{kg}$ /día mientras que los animales Jersey crecieron a una tasa de 0,6266 kg/día. En el cruce 1/2 Reyna - 1/2 Jersey la tasa de crecimiento de los machos fue $25 \%$ superior al de las hembras, mientras que en Jersey puro el sexo femenino fue $17 \%$ menos eficiente que el masculino para ganar peso.
\end{abstract}

Palabras clave: Ganado Reyna, doble propósito, desarrollo de novillas, bovinos, producción animal.

\begin{abstract}
Comparison of Reyna-Jersey animals weight weaning and pure breed Jersey animals, during growing period. The experiment was carried out during 2006 and 2007 at Experimental Station Alfredo Volio Mata of the University of Costa Rica where the weigh weaning of six crossed $1 / 2$ Reyna- $1 / 2$ Jersey animals and six pure breed Jerseys was evaluated during growth, to determine advantages and differences when Reyna breed is included in specialized systems. The $1 / 2$ Reyna- $1 / 2$ Jersey heifers gained weight at a rate of $0,7265 \mathrm{~kg} /$ day while the others did at $0,6266 \mathrm{~kg} /$ day. In $1 / 2$ Reyna- $1 / 2$ Jersey heifers, the males growing rate was $25 \%$ higher than females, and their homologues showed that females were $17 \%$ less efficient than males.
\end{abstract}

Key words: Reyna breed, double purpose, heifers development, bovines, animal production.

\section{INTRODUCCIÓN}

En Latinoamérica, la ganadería es una actividad que se ha caracterizado por su gran aporte para la economía, para el 2002 el inventario de animales bovinos en esta región alcanzó 359 millones de cabezas de las cuales el 11,1\% correspondió a animales en plena etapa productiva de leche (FAOSTAT 2002; citado por Rivas y Holmann 2003).
La explotación lechera se ha desarrollado con un grado de especialización elevado, basada en un manejo de tierras sumamente intensivo y respaldado por el uso de pasturas mejoradas y alta tecnología, lo que implica inversión en equipo e infraestructura, la cual es cuatro veces mayor que la que se da para la actividad de carne (Holmann et al. 2002), soportado por un flujo de caja permanente.

\footnotetext{
1 Recibido: 29 de mayo, 2007. Aceptado: 26 de agosto, 2008. Trabajo financiado por la Vicerrectoría de Investigación de la Universidad de Costa Rica. San José, Costa Rica. Proyecto VI-737-97-006.

2 Estación Experimental Alfredo Volio Mata, Facultad de Ciencias Agroalimentarias, Universidad de Costa Rica. Cartago, Costa Rica. fabian.vargas@ucr.ac.cr
} 
Los sistemas de producción de carne tradicionalmente han sido enfocados bajo métodos extensivos y con pasturas de baja calidad, además el manejo del retorno monetario depende de la periodicidad del esquema productivo establecido (cría, desarrollo o engorde). El proceso evolutivo de ambos sistemas engendró una serie de racionalidades productivas adversas para cierto grupo de productores (Carrizales et al. 2000), sobre todo para aquellos que carecen de solvencia económica para establecer una lechería especializada, o con pocas extensiones de terreno que les impide volcarse a la producción extensiva de carne, además, el proceso de urbanización está acaparando las mejores áreas para la producción agropecuaria (Simpson y Conrad 1993, McDowell et al. 1996), lo que ha generado su desplazamiento hacia áreas con menor capacidad productiva.

Ante los inconvenientes planteados, surgen las explotaciones de doble propósito cuya finalidad es una producción continua de leche y sus derivados, pero además trata de mantener en la finca los machos (desechados en las lecherías desde los primeros días de nacidos), que se convierten en fuentes de ingresos alternas cuando se venden para carne, o en su defecto para el consumo interno del grupo familiar, considerando que el precio de la misma ha ocasionado una reducción en su consumo (Simpson y Conrad 1993).

Bajo este esquema el productor obtiene mejores beneficios que invertir en cajas de ahorro o compra de dólares, que a largo plazo han sido menos rentables que las inversiones ganaderas, además le permite contrarrestar el efecto de la inflación acelerada (Estrada 1995). Adicionalmente, es un sistema flexible que se ajusta a los altibajos de los precios, y aunque la rentabilidad expresada como retorno al capital invertido ha declinado en todos los sistemas ganaderos, el doble propósito ha sufrido mucho menos que las explotaciones especializadas (Rivas y Holman 2003).

Tradicionalmente, como doble propósito se han manejado cruces entre razas lecheras como Holstein o Jersey con animales Cebú, no obstante, hay una raza que se apega más a lo deseado en un sistema combinado, se trata de la raza Reyna, conocida también como el ganado criollo centroamericano.
Esta raza encaja muy bien en el concepto de doble propósito cuya característica primordial es la supervivencia bajo condiciones de estrés, mala alimentación, pobre manejo, y condiciones no aptas para el animal especializado que tendría consecuencias negativas en su rendimiento (Simpson y Conrad 1993). Además, en el trópico puede producir leche con mayor contenido de nutrientes aunque en menor volumen, y su carne puede ser mucho más magra en comparación con animales especializados sometidos al mismo esquema de manejo. Estas condiciones han permitido considerar al doble propósito como la columna vertebral de la ganadería tropical (Urdaneta 2007).

Estos animales se consideran descendientes directos de los traídos por lo españoles durante las expediciones que realizó Cristóbal Colón en su segundo viaje en 1493 (Primo 1992, Salazar y Cardoso 2007), este grupo se asentó en la isla La Española (República Dominicana), sin embargo su introducción fue a partir de 1524, donde el resto del continente americano comenzó a poblarse exitosamente de bovinos y a implantarlos en sus sistemas ecológicos (Salazar y Cardoso 2007).

Con el objetivo de incrementar los rendimientos productivos y complementar genotipos se ha implementado el cruce entre animales lecheros especializados (Jersey o Holstein) con animales de razas criollas, con resultados satisfactorios. Enfocado en esta teoría fue que se desarrolló el presente trabajo con la intensión de cuantificar las diferencias y posibles ventajas que se pueden infundir al implementar la raza Reyna en un sistema especializado.

\section{MATERIALES Y MÉTODOS}

\section{Localización}

Este trabajo se llevó a cabo durante el 2006 y 2007 en la Estación Experimental de Ganado Lechero Alfredo Volio Mata de la Universidad de Costa Rica, localizada a $1.542 \mathrm{msnm}$, en Ochomogo de Cartago, con una temperatura media $19,5^{\circ} \mathrm{C}$ y una precipitación promedia de $2.050 \mathrm{~mm}$. 


\section{Materiales experimentales}

Como grupo experimental se utilizaron 12 animales, seis de la raza Jersey de los cuales tres fueron hembras y tres machos, y seis animales $1 / 2$ Reyna- $1 / 2$ Jersey en igual cantidad de hembras y machos, los cuales fueron sometidos al mismo sistema de alimentación y manejo desde el nacimiento hasta alcanzar la edad de 400 días aproximadamente.

Desde el momento del nacimiento se llevó un control del peso corporal y de la ganancia de peso que manifestaron los animales. El pesaje se realizó mes a mes y en forma individual utilizando para tales efectos una romana calibrada, marca Ag Tronic, Inc. con capacidad de $1.400 \mathrm{~kg}$.

El grupo experimental se manipuló bajo un sistema de pastoreo rotativo con Estrella Africana ( $C y$ nodum nlemfluensis), el periodo de ocupación fue de dos días con un descanso de 28 días. Cada aparto se fertilizó un día después de que los animales salieron de pastoreo con una cantidad aproximada de $250 \mathrm{~kg} / \mathrm{ha} /$ año de nitrógeno.

En el Cuadro 1 se presenta el manejo alimenticio que se le brindó al grupo experimental.

En el Cuadro 2 se detalla el contenido nutricional de las fuentes comerciales utilizadas para la alimentación de

Cuadro 1. Esquema alimenticio al cual fue sometido el grupo experimental de bovinos. Cartago, Costa Rica, 2007.

\begin{tabular}{clc}
\hline $\begin{array}{c}\text { Edad } \\
\text { (días) }\end{array}$ & \multicolumn{1}{c}{ Fuente } & Cantidad/día \\
\hline $1-3$ & Calostro & $3-4 \mathrm{~kg}$ \\
$3-90$ & Leche & $4 \mathrm{~kg}$ \\
$3-75$ & $\begin{array}{l}\text { Concentrado comercial para } \\
\text { inicio de terneras }\end{array}$ & $0,150-0,600 \mathrm{~kg}$ \\
$75-90$ & $\begin{array}{l}\text { Concentrado comercial para } \\
\text { desarrollo de terneras }\end{array}$ & $0,600-1 \mathrm{~kg}$ \\
60 a 400 & $\begin{array}{l}\text { Estrella africana (Cynodum } \\
\text { nlemfluensis) }\end{array}$ & Ad-libitum \\
90 a 450 & $\begin{array}{l}\text { Concentrado comercial para } \\
\text { desarrollo de terneras }\end{array}$ & $1,5-2 \mathrm{~kg}$ \\
\hline
\end{tabular}

ISSN: 1021-7444
Cuadro 2. Contenido bromatológico de los concentrados comerciales empleados en la alimentación de los bovinos. Cartago, Costa Rica, 2007.

\begin{tabular}{lcc}
\hline Componente $^{1}$ & $\begin{array}{c}\text { Inicio de } \\
\text { terneras }\end{array}$ & $\begin{array}{c}\text { Desarrollo de } \\
\text { terneras }\end{array}$ \\
\hline Materia seca, \% & 87,0 & 87,0 \\
Proteína cruda, \% & 18,0 & 16,0 \\
Energía digestible & & \\
Kcal/kg & $3.500,0$ & $3.150,0$ \\
\hline
\end{tabular}

${ }^{1}$ Componentes analizados en el Laboratorio de Bromatología de la Estación Experimental de Ganado Lechero Alfredo Volio Mata, Universidad de Costa Rica.

los animales durante el periodo de evaluación, el componente forrajero se les introdujo a partir de los 60 días, el cual fue cosechado y se les suministró en la canoa, a los 90 días los animales se destinaron a pastoreo.

Los datos de peso y ganancia de peso fueron analizados con el PROC GLM de SAS, versión 8.2 (SAS, 1999), con el siguiente modelo:

$$
\mathrm{Y}_{\mathrm{ijkl}}=\mu+\mathrm{R}_{\mathrm{i}}+\mathrm{S}_{\mathrm{j}}\left(\mathrm{R}_{\mathrm{i}}\right)+\beta \mathrm{E}_{\mathrm{k}}+\mathrm{e}_{\mathrm{ijkl}}
$$

$\mu=\quad$ media experimental.

$\mathrm{R}_{\mathrm{i}=} \quad$ efecto de i-ésimo grupo racial.

$\mathrm{S}_{\mathrm{j}}\left(\mathrm{R}_{\mathrm{i}}\right)=$ efecto anidado del j-ésimo sexo dentro del i-ésimo grupo racial.

$\mathrm{E}_{\mathrm{k}}=\quad$ efecto de la k-ésima edad.

$\mathrm{e}_{\mathrm{ijkl}}=$ error experimental del i-ésimo grupo racial, j-ésimo sexo, k-ésima edad y l-ésima observación experimental.

\section{RESULTADOS Y DISCUSIÓN}

Los animales $1 / 2$ Reyna - $1 / 2$ Jersey presentaron una mejor tasa de crecimiento que los animales Jersey puros superándolos en un 16\% ( $\mathrm{p}<0,001)$. Los primeros ganaron peso a razón de $0,727 \mathrm{~kg} /$ día mientras que los animales puros promediaron 0,627 kg/día. Este comportamiento se puede observar en la Figura 1. Ambos grupos aventajan los resultados obtenidos por Vargas y Boschini (2007) cuando evaluaron el crecimiento de novillas Jersey puras suplementadas con harina de banano, los cuales indican valores de ganancia entre 


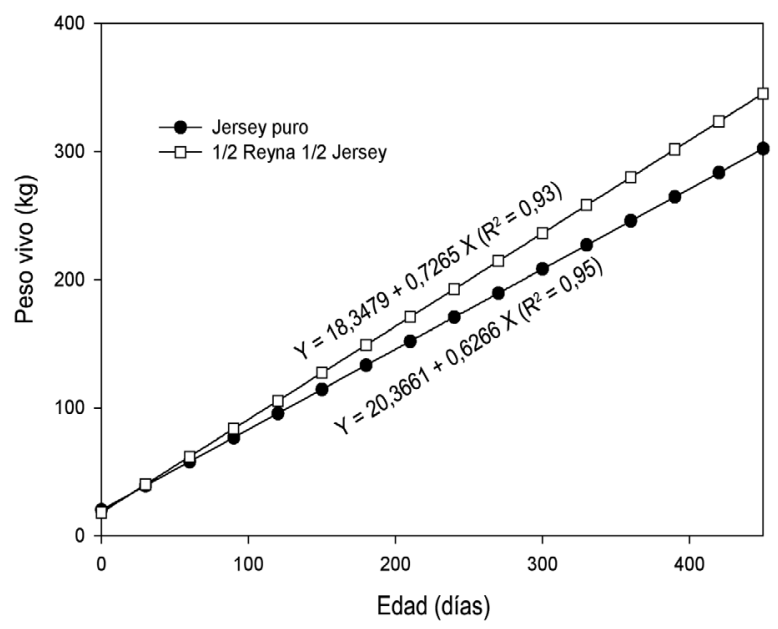

Figura 1. Crecimiento diario diferenciado por grupo racial (Jersey puro y Reina-Jersey). Cartago, Costa Rica, 2007.

0,419 y $0,552 \mathrm{~kg} / \mathrm{día}$; no obstante, el primer grupo muestra similitud con lo manifestado por Romero (2005), quien aduce que animales con pesos menores a $340 \mathrm{~kg}$ tienen ganancias de hasta $0,800 \mathrm{~kg} / \mathrm{d}$ ía, no obstante, ambos cumplen con lo propuesto por Field (2001) quien asegura que las novillas antes de su primer servicio deben presentar un crecimiento de entre 0,570 a $0,790 \mathrm{~kg} /$ día. Algunos estudios consideran que ganancias superiores a los $0,600 \mathrm{~kg}$ /día podrían tener efectos contraproducentes en la producción de leche durante la primera lactancia (Pirlo et al. 1997), lo que sería importante analizar en ambos grupos durante su primer periodo productivo.

Como se observa en la Figura 1, ambas razas mantuvieron un crecimiento similar antes de los 30 días de edad, y su peso al nacimiento en promedio fue de 28,66 $\mathrm{kg}$ para el grupo $1 \frac{1}{2}$ Reyna- $1 / 2$ Jersey, y $24,33 \mathrm{~kg}$ para el grupo puro. De acuerdo con Wattiaux (2003) lo ideal es que al nacimiento el peso se encuentre entre 25 y $30 \mathrm{~kg}$ para animales de la raza Jersey. Si se compara el grupo experimental con esta aseveración, los animales puros no cumplieron con ese objetivo, ni siquiera se acercaron al límite inferior. Las vacas madres de ambos grupos raciales recibieron el mismo manejo, alimentación y presentaron similar condición corporal. Por otro lado los animales con $1 / 2$ encaste si se mantuvieron en ese rango, por lo que se puede asumir que la raza Reyna aporta un vigor de peso al nacimiento lo que se traduce en la producción de terneros fuertes al nacimiento con una reducida tasa de mortalidad en los primeros meses de vida (Primo 1992). A partir del día 30, las diferencias en las ganancias de peso entre los grupos raciales fueron significativas $(\mathrm{p}<0,001)$.

La conducta de crecimiento que manifiestaron los animales $1 / 2$ Reyna- $1 / 2$ Jersey se relaciona a lo suscrito por McDowell et al. (1996) quien menciona que cuando se cruzan razas especializadas en producción de leche con razas criollas, la primera generación manifiesta mayor vigor que otros cruces bajo condiciones ambientales de estrés, lo que puede mejorar los rendimientos en la tasa de crecimiento, la producción de leche y la capacidad reproductiva.

Las diferencias también se aprecian en el peso al destete, el cual se dio a los 90 días; las hembras Jersey puras manifestaron pesos promedios de $70 \mathrm{~kg}$ mientras que las hembras cruzadas se destetaron a un peso de $77,93 \mathrm{~kg}$ superando a las primeras en un $10 \%$. Por su parte los machos Reyna-Jersey a los 90 días superaron a los machos puros en un $15 \%$, alcanzando un peso al destete de $87 \mathrm{~kg}$ contra 81 de los machos puros.

En la Figura 2, se observa una comparación de los dos grupos raciales utilizados en la prueba, pero tomando en consideración el comportamiento demostrado entre sexos donde las diferencias resultaron ser

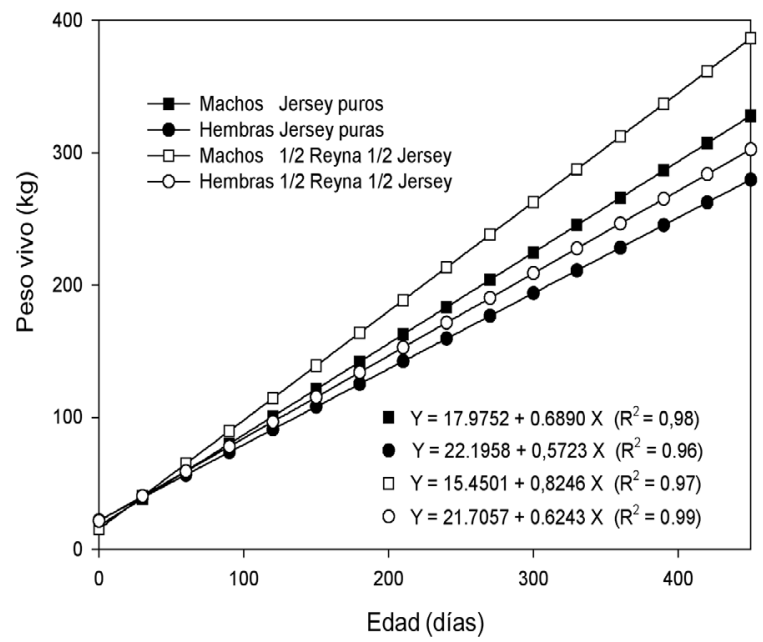

Figura 2. Crecimiento diario diferenciado por sexo y grupo racial (Jersey puro y Reina-Jersey). Cartago, Costa Rica, 2007. 
altamente significativas entre sexo dentro de los grupos raciales $(\mathrm{p}<0,001)$.

Al analizar el sexo en cada grupo racial, para el cruce $1 / 2$ Reyna $-1 / 2$ Jersey se logró apreciar que, a pesar de que las hembras manifestaron una tasa de crecimiento a razón de $0,6243 \mathrm{~kg} /$ día, su rendimiento respecto a los machos fue marcadamente inferior. Los machos crecieron a razón de $0,8246 \mathrm{~kg} /$ día, lo que supera a las hembras en un $25 \%$ durante un periodo de 400 días. O expresado en otros términos, los machos son 1,32 veces más veloces en ganar peso que las hembras. En cuanto a los animales Jersey puros, la conducta de superioridad en el aumento de la masa corporal de los machos sobre las hembras dio como resultado que las últimas tienen una tasa de crecimiento inferior a la de los machos en un $17 \%$, la cual se manifestó durante el periodo de prueba.

Los machos $1 \frac{1}{2}$ Reyna $1 / 2$ Jersey en comparación con los machos Jersey puros, mostraron ganancias de peso de $0,8246 \mathrm{~kg} /$ día mientras que los segundos aumentaron su masa corporal a razón de 0,6890 $\mathrm{kg} /$ día. La diferencia de crecimiento entre ambos fue altamente significativa $(\mathrm{p}<0,001)$, siendo los primeros $20 \%$ más veloces que los animales puros. La misma comparación se hizo entre hembras de diferente raza, a pesar de que las diferencias entre ambos grupos fueron altamente significativas $(\mathrm{p}<0,001)$, las Jersey ganaron peso por día a razón de $0,5723 \mathrm{~kg}$, apenas fueron menos veloces que las $1 / 2$ Reyna - 1/2 Jersey $(0,6890$ $\mathrm{kg} /$ día) en un $9 \%$. Cabe mencionar que el crecimiento del grupo femenino fue favorable de acuerdo con lo mencionado por Wattiaux (2003), quien indica que si las novillas ganan peso a tasas mayores de 0,550 kg/día alcanzarán pubertad entre los 12 y 14 meses de edad, se puede lograr un empadre a los 15 meses y un parto a los 24 meses en un estado de desarrollo adecuado, asegurando un parto sin dificultad y un buen rendimiento en su primer lactancia.

La ganancia de peso del grupo de hembras $1 / 2$ Reyna $-1 / 2$ Jersey, superó lo obtenido por Acosta y Randel (2002), cuando probaron la pubertad en animales mestizos Bos taurus /Bos indicus alimentadas con dos dietas, una con un complemento concentrado, y la otra con una mezcla de concentrado con Monensina sódica bajo un sistema de pastoreo, los resultados obtenidos por estos investigadores no superaron $0,400 \mathrm{~kg}$ de ganancia de peso diario, muy por debajo de lo obtenido en el presente estudio, donde las novillas Reyna lograron en promedio $0,689 \mathrm{~kg} /$ día.

Los machos $1 / 2$ Reyna - $1 / 2$ Jersey manifestaron una conducta acelerada de crecimiento que se despega del resto del grupo experimental a partir del día 30, como se aprecia en la Figura 2, mientras que los machos Jersey se mantiene muy cerca del resto del grupo hasta los 110 días de edad que es cuando comienza a aumentar con más rapidez su masa corporal.

\section{CONCLUSIONES}

La inclusión de genética de animales Reyna sobre vacas Jersey favoreció el crecimiento de las novillas durante el primer año de desarrollo.

En el encaste $1 / 2$ Reyna - $1 / 2$ Jersey la tasa de crecimiento de los machos superó a las hembras en un $25 \%$, mientras que en Jersey puro la ganancia de peso del sexo femenino fue $17 \%$ inferior al de los machos.

Los genes Reyna proporcionaron mayor capacidad de crecimiento que los genes de los animales Jersey, capacitándolos para resistir mejor los periodos críticos propios del desarrollo, y aporta el componente carne a las explotaciones lecheras con machos de mejor rendimiento en cuanto a la ganancia de peso diaria.

Se debe analizar la conducta de producción láctea de estos animales para conocer el efecto real de la genética Reyna sobre los rendimientos y la calidad de la leche para los sistemas de doble propósito.

\section{LITERATURA CITADA}

Acosta, R; Randel, R. 2002. Pubertad en novillas mestizas Bos taurus/Bos indicus alimentadas con concentrado, concentrado con Monensina y pasto alemán (Echinochloa polystachya H.B.K: Hitchcock). Overton Texas. Zootecnia Tropical 20(2): 319-339.

Estrada, R. 1995. Incidencia de las políticas económicas en la conservación de los recursos naturales en la zona Andina. Consorcio para el Desarrollo Sostenible de la 
Ecoregión Andina (CONDESAN). Red de pastizales andinos (REEPAN). Quito, Ecuador. 79 p.

Carrizales, H; Paredes, L; Capriles, M. 2000. Estudio del funcionamiento tecnológico en ganaderías de doble propósito en la zona de Santa Bárbara municipio Colón. Zootecnia Tropical 18(1): 29-77.

Field, J. 2001. Manejo y alimentación de las novillas de reemplazo para la producción de carne. Ontario, Canadá. (En línea) Consultado 14 febrero 2007. Disponible en: www.geocities.com/raydelpino_2000/ manejoyalimentacionnovillasdereemplazo.html

Holmann, F; Rivas, L, Carulla, J; Giraldo, L; Guzman, S; Martinez, M; Rivera, B; Medina, A; Farrow, A. 2003 Evolution of Milk Production Systems in Tropical Latin America and its interrelationship with Markets: An Analysis of the Colombian Case. Journal of Livestock Research for Rural Development (15): 9.

McDowell, R; Wilk, J; Talbot, C. 1996. Economic viability of crosses of Bos taurus and Bos indicus for dairying in warm climates. Journal of Dairy Science 79: 1292-1303.

Pirlo, G; Capelleti, M; Marcheto, G. 1997. Effects of energy and protein allowances in the diet of prepuberal heifers and growth and milk production. Journal of Dairy Science 80: 121-133.

Primo, A. 1992. El ganado bovino ibérico en las Américas: 500 años después. Archivo Zootecnia 41 (extra): 421-432.

Rivas, L; Holmann, F. 2003. Sistemas de doble propósito y su viabilidad en el contexto de los pequeños y medianos productores en América Latina tropical. Consultado 13 febrero 2007. Disponible en: www.virtualcentre. org/es/ele/conferencia4/artículos/Ponencias5.htm

Romero, C. 2005. Manejo de la recría en una explotación de vacuno de leche (I). Madrid, España. Consultado el 13 de febrero del 2007. Disponible en: www.eumedia. es/artículos/mg/177s_vacuno.html

Salazar, J; Cardoso, A. 2007. Desarrollo del Ganado criollo en América Latina: Resumen histórico y distribución actual. Consultado 13 febrero 2007. Disponible en: www.fao.org/docrep/009/ah223s/AH223S04.htm

SAS (Statiscal Analysis System). 1999. SAS User's Guide: Statistics (Version 8.2 Ed) SAS Institute Inc. Cary, NC. $373 p$.

Simpson, J; Conrad, J. 1993. Intensification of cattle production systems in Central America: Why and When. Journal of Dairy Science 76:1744-1752.

Urdaneta, F. 2007. Sistemas de producción ganaderos con bovinos de doble propósito. Consultado 13 febrero 2007. Disponible en: ww.gdp.infoagro.ve/Ganaderos BovinosDP.htm

Vargas, C; Boschini, C. 2007. Suplementación con harina de banano sobre la ganancia de peso en novillas Jersey. Agronomía Mesoamericana 18(1): 19-25.

Wattiaux, A. 2003. Crianza de terneras del nacimiento al destete. Tasa de crecimiento. (En línea). Consultado 14 abril 2007. Wisconsin, Estados Unidos. Disponible en: www.babcock.cals.wisc.edu/downloads/de_html/ ch34.es.html 